\title{
The study of MDCT of Radiation dose in the department of Radiology of general hospitals in the local area
}

\author{
Jungsub Shin \\ Department of Radiologic Technology, Sunlin college

\section{일 지역 종합병원 영상의학과 MDCT선량에 대한 연구} \\ 신정섭 \\ 선린대학교 방사선과*
}

\begin{abstract}
The difference of radiation dose of MDCT due to different protocols between hospitals was analyzed by CTDI, DLP, the number of Slice and the number of DLP/Slice in 30 cases of the head, the abdomen and the chest that have 10 cases each from MDCT examination of the department of diagnostic imaging of three general hospitals in Gyeongsangbuk-do. The difference of image quality, CTDI, DLP, radiation dose in the eye and radiation dose in thyroid was analyzed after both helical scan and normal scan for head CT were performed because a protocol of head CT is relatively simple and head CT is the most frequent case.

Head CT was significantly higher in two-thirds of hospitals compared to A hospital that does not exceed a CTDI diagnostic reference level (IAEA 50mGy, Korea 60mGy) $(\mathrm{p}<0.001)$. DLP was higher in one-third of hospitals than a diagnostic reference level of IAEA 1,050mGy.cm and Korea 1,000mGy.cm and two-thirds exceeded the recommendation of Korea and those were significantly higher than A hospital that does not exceed a diagnostic reference level $(\mathrm{p}<0.001)$.

Abdomen CT showed 119mGy that was higher than a diagnostic reference level of IAEA 25mGy and Korea $20 \mathrm{mGy}$ in one-third. DLP in all hospitals was higher that Korea recommendation of $700 \mathrm{mGy} . \mathrm{cm}$. Among target hospitals, C hospital showed high radiation dose in all tests because MPR and 3D were of great importance due to low pitch and high Tube Curren.

To analyze the difference of radiation dose by scan methods, normal scan and helical scan for head CT of the same patient were performed. In the result, CTDI and DLP of helical CT were higher $63.4 \%$ and $93.7 \%$ than normal scan $(p<0.05, p<0.01)$. However, normal scan of radiation dose in thyroid was higher $87.26 \%$ $(\mathrm{p}<0.01)$. Beam of helical CT looked like a bell in the deep part and the marginal part so thyroid was exposed with low radiation dose deviated from central beam. In addition, helical scan used Gantry angle perpendicularly and normal scan used it parallel to the orbitomeatal line. Therefore, radiation dose in thyroid decreased in helical scan. However, a protocol in this study showed higher radiation dose than diagnostic reference level of KFDA. To obey the recommendation of KFDA, low Tube Curren and high pitch were demanded. In this study, the difference of image quality between normal scan and helical scan was not significant. Therefore, a standardized protocol of normal scan was generally used and protective gear for thyroid was needed except a special case.
\end{abstract}


We studied a part of CT cases in the local area. Therefore, the result could not represent the entire cases. However, we confirmed that patient's radiation dose in some cases exceeded the recommendation and the deviation between hospitals was observed. To improve this issue, doctors of diagnostic imaging or technologists of radiology should perform CT by the optimized protocol to decrease a level of CT radiation and also reveal radiation dose for the right to know of patients. However, they had little understanding of the situation. Therefore, the effort of relevant agencies with education program for CT radiation dose, release of radiation dose from $\mathrm{CT}$ examination and addition of radiation dose control and open CT contents into evaluation for hospital services and certification, and also the effort of health professionals with the best protocol to realize optimized CT examination.

Key Words : MDCT of Radiation dose, Diagnostic reference level, The optimization of protection, Radiation dose.

\section{요야}

경상북도에 소재한 3 개 종합병원 영상의학과의 $\mathrm{MDCT}$ 검사 중 두부, 복부, 흥부 각 10 건씩 30 건을 대상으로 CTDIl, DLP, Slice 수, DLP/Slice 수를 조사하여 병원 간 프로토콜의 차이로 인한 MDCT의 피폭선량의 차이를 분석하 였고, CT검사의 가장 많은 검사건수를 차지하고 프로토콜이 비교적 단순한 두부 CT를 Helical Scan과 Normal Scan으 로 2회 실시하여 영상의 화질, CTDI, DLP, 안구의 피폭선량, 갑상선의 피폭선량의 차이를 분석하였다.

두부CT에서 조사대상 병원의 3 분의 2 에서 CTDI 참조준위(IAEA $50 \mathrm{mGy}$, 우리나라 $60 \mathrm{mGy}$ )를 초과하지 않은 A병 원에 비하여 유의하게 높았다( $\mathrm{p}<0.001)$. DLP에서 조사병원의 3 분의 1 은 참조준위 IAEA $1,050 \mathrm{mGy} . \mathrm{cm}$, 우리나라 $1,000 \mathrm{mGy} . \mathrm{cm}$ 의 권고량 보다 높았고, 3 분의 2 가 우리나라의 권고량을 초과하고 있었다. 참조준위를 초과하지 않은 $\mathrm{A}$ 병원에 비하여 유의하게 높았다 $(\mathrm{p}<0.001)$.

Abdomen CT에서도 3 분의 1은 CTDI 참조준위 IAEA $25 \mathrm{mGy}$, 우리나라 $20 \mathrm{mGy}$ 보다 높은 $119 \mathrm{mGy}$ 를 보였고, DLP 에서는 모든 조사대상 병원이 우리나라 권고량 $700 \mathrm{mGy} . c m$ 보다 높았다. 조사대상 병원 중 모든 검사에서 높은 선량을 보인 C병원은 MPR, 3D 검사의 비중이 높아 낮은 pitch, 높은 관전류 검사로 인한 피폭선량이 높았다.

Scan 방법에 따른 피폭선량의 차이를 분석하고자 동일환자의 두부CT를 Normal scan과 Helical scan으로 각각 실시 하여 분석한 결과 CTDI 및 DLP에서 Helical CT가 Normal scan에 비해 $63.4 \%, 93.7 \%$ 높은 선량을 보였다( $<<0.05$, $\mathrm{p}<0.01)$. 그러나 갑상선의 피폭선량은 Normal scan이 $87.26 \%$ 높았다 $(\mathrm{p}<0.01)$. Helical CT의 선속은 종심부와 변연 부의 모양이 종의 형태를 취하고 있어 두부CT에서 갑상선은 중심선속에서 벗어난 적은 선량으로 피폭된다. 또한 Helical scan시 Gantry 각을 수직으로 사용하였고, Normal scan시에는 Orbitomeatal line에 평행으로 정렬된 Gantry 각을 사용하여 Helical scan에서 갑상선은 피폭선량이 감소하였다. 그러나 본 연구에서 사용된 프로토콜은 식약청의 표준준위에 비해 높은 피폭선량을 보여 식약청의 권고량을 지키기 위해서는 낮은 관전류 높은 Pitch의 사용이 요구되 었다. 이번 연구에서 Normal scan과 Helical scan에 따른 화질의 차이는 없는 것으로 분석되어 특별한 경우가 아니면 Normal scan의 표준화된 프로토콜을 사용하고 갑상선의 보호장구를 사용하는 것이 필요하였다.

이번 연구는 일지역의 CT검사 중 일부를 조사하여 분석하였으므로 CT검사의 전체를 평가하는데 무리가 있었다. 그러나 경우에 따라 환자피폭선량의 가이드 권고량을 초과하고 있음을 알 수 있었고, 병원 간의 피폭선량 편차도 있음 을 확인 할 수 있었다. 이것을 개선하기 위하여 영상의학과 의사 및 방사선사는 $\mathrm{CT}$ 방사선량을 줄이는 최적화된 프로 토콜로 CT검사를 시행해야 하고, 환자의 알권리를 위하여 피폭선량은 공개되어야 한다. 그러나 아직 많은 의사들과 방 사선사는 이에 대한 인식이 부족하므로 개선을 위하여 CT선량 저감화의 교육프로그램, CT검사에 따른 피폭선량의 공 개, 병원의 서비스평가 및 병원인증제 평가항목에 CT검사 피폭선량관리 및 공개항목을 추가 등의 관련기관의 노력과 의료종사자가 CT검사에서 행위의 최적화를 실현하는 최선의 프로토콜을 사용하는 노력이 필요하였다.

중심단어: MDCT선량, 피폭선량, 참조준위, 방호의 최적화 


\section{I. 서론}

인공방사선에 의한 장애는 Roentgen에 의해 1895년 $\mathrm{X}$ 선이 발견되었고 그 다음해에 $\mathrm{X}$ 선관 제조기술자의 손에 피부염이 생기고 머리가 빠지는 탈모현상이 최 초의 인공방사선장애로 기록되고 있으며 그 이후부터 방사선에 대한 두려움이 시작되었다. 그 후 세계 2 차 대전 중 일본 본토에 투하된 원자폭탄은 전 인류를 방 사선 공포에 휩싸이게 하였다. 그러나 인류의 발전을 많은 에너지를 필요하게 되었고 지구의 온난화와 함 께 녹색에너지로 원자력에너지를 보는 새로운 시각은 원자력에너지의 평화적 사용에 초점이 맞추어져 사용 되었다. 그러나 2011년 3월 11일 일본 동북부 지방을 강타한 규모 9.0 의 대지진으로 인해 쓰나미가 발생하 였고 이로 인해 원자로에 전원이 중단되면서 원자로 를 식혀 주는 긴급 노심냉각장치가 작동을 멈췄고, 3 월 12 일 1 호기에서 수소폭발이 일어나는 대재앙이 발 생하였다.

인류는 지금도 방사선의 공포에서 벗어나지 못하고 있는 실정이다. 의료용 방사선에 대한 두려움도 예외 는 아니다. 인류가 받는 총 방사선 피폭 중 인공방사 선에 의한 피폭은 $15 \%$ 정도이고 인공방사선피폭 중 의료에서의 방사선 피폭은 약 $80 \sim 90 \%$ 를 차지하고, 방 사선검사건수 중 전산화 단층촬영장치(Computed tomography, 이하 CT) 검사건수는 전체 방사선검사건 수의 약 $13 \%$ 이고 방사선량 기준으로 의료피폭의 약 $30 \%$ 정도는 CT검사 때문인 것으로 사료된다 ${ }^{[7]}$.

CT는 인체에 대한 단면적 촬영을 가능케 하기 위해 컴퓨터와 기존의 X-선 장비를 결합한 혁명적인 진단 장비로서, 1971년 물리학자 G.Hounsfield와 의사 J. Ambrose에 의해 의학 영상분야에 도입된 이후로 CT는 진단에 있어 필요불가결한 장비가 되었다 ${ }^{[8]}$. 또한, 1990년도 후반 개발되어 도입된 Multi-detector CT(MD $\mathrm{CT}$ )는 기존의 CT장비에 비해 X-선관(tube)의 1 회 회전 으로 한번에 4장의 영상을 얻을 수 있는 형태가 개발 되고, 그 이후 기술적인 발달을 이어서 $8,16,32,64$ 개 의 검출기(detector)를 장착한 $\mathrm{CT}$ 가 개발됨에 따라 한 번에 훨씬 더 많은 영상을 얻는 것이 가능해 졌으며다, 최근에는 640 개의 검출기를 장착된 MDCT도 보급되어
사용되고 있는 실정이다

$\mathrm{CT}$ 의 발전은 MDCT로 변모하였고, 이전의 단일 슬 라이스 CT로는 검사 할 수 없었던 관상동맥, 폐혈관색 전증에서 가장 정확한 진단율을 가지는 가장 처음 시 행해야 하는 검사가 되었다 ${ }^{[16-17]}$. 이러한 진단영역의 확장은 이전 보다 더 많은 검사가 이루어지게 하여 기 술의 발달과 의학의 진보에 따라 수반되는 문제로 의 료용 방사선 피폭은 검사가 늘어남에 따라 증가할 수 밖에 없다. 특히 CT 사용의 증가로 인하여 지난 십여 년 간 의료용 방사선 피폭이 급격히 증가했다 ${ }^{[22]}$.

의료용 방사선피폭의 증가를 뒷받침하는 National Council on Radiation Protection and Measurements 의 2006 년도 보고에 의하면 미국에서 전 국민의 1 인당 방 사선 피폭량은 1980 년대 초반의 $3.6 \mathrm{mSv}$ 에서 2006년 $6.2 \mathrm{mSv}$ 로 증가하였다. 이 자료에 의하면 증가된 방사 선 피폭의 원인은 대부분 의료용 방사선 피폭이다. 1980년대 초의 의료 용 방사선 피폭은 미국 국민 1 인 당 $0.53 \mathrm{mSv}$ 에서 2006 년 $3.0 \mathrm{mSv}$ 로 늘었다. 또한 1 인당 방사선 피폭량에서 의료용 방사선 피폭이 차지하는 비율은 $15 \%$ 에서 $48 \%$ 로 증가하였다 ${ }^{[3]}$.

방사선피폭의 관리는 국제 방사선방호기준 권고기 관이 있고 국가에서 비교적 엄격한 법령에 의하여 관 리되고 있다. 그러나 방사선 관계종사자에 비해 환자 의 방사선피폭은 법률의 제재를 받지 않게 되는데, 환 자는 개개인이 처한 의학적 상황에 따라 검사의 이득 과 방사선 피폭의 위험을 평가하여야 하므로 일률적 인 선량한도를 정해 둘 수 없기 때문이다 ${ }^{[4]}$. 그러므로 환자의 방사선피폭은 방사선 피폭을 동반하는 검사를 의뢰하는 임상의사 또는 검사를 시행하는 방사선사, 판독하는 영상의학과 의사의 방사선 위해에 대한 인 지도가 중요하다. 의사의 방사선위해에 대한 인지도를 연구한 결과를 보면 CT 검사에서의 방사선 위해는 대 부분의 의사에 의하여 저평가 되고 있다. 선행연구에 의하면 영상의학과 의사의 $76 \%$, 응급의학과 의사의 $73 \%$, 환자의 $100 \%$ 가 CT 검사에서의 방사선 피폭량을 과소평가 하고 있다 ${ }^{[14]}$ MDCT는 여러 가지 장점이 있 음에도 불구하고 장치 하드웨어의 문제로 X-선관과 검출기의 거리가 가까워지고, 검사의 고속화와, 더욱 얇은 슬라이스 두께를 이용하므로 이에 따른 잡음 (noise)이나 화질 향상을 위해 방사선 피폭선량이 높다 
는 연구결과가 나온 바 있고 ${ }^{[9]}$. СТ검사시 각 의료기관 의 검사프로토콜과 CT장비의 모델에 따라 동일한 부 위를 검사하여도 환자선량에는 차이가 있다 ${ }^{[8]}$. 이러한 이유는 $\mathrm{CT}$ 의 화질향상을 우선시 하는 판단기준에 자 유롭지 못한 방사선사 역시 방사선피폭량에 대하여 과소평가하는 것으로 보인다.

국제적으로 일반 국민에 대한 의료용 방사선 피폭 을 줄이고자 하는 노력은 여러 정부 차원에서 이루어 지고 있다. 미국 캘리포니아주는 법령을 통하여 환자 의 방사선 피폭을 규제하려고 한다. 2010년에 통과하 여 2012년 7월 1일 부터 효력을 갖게 되는 이 법령은 CT를 사용하는 모든 기관이 환자에 대한 방사선 피폭 량을 기록하고 1 년 단위로 관계 기관의 요청이 있는 경우 제시하도록 하고 있다 ${ }^{[1]}$. 우리나라에서는 환자의 방사선피폭을 규제하는 법령 및 방사선 피폭량을 기 록하는 관계규정은 없고 정기적으로 CT장비의 성능을 평가하여 부적합 CT장비를 사용금지 하는 시스템을 도입하고 있다.

전 세계적으로 진단검사를 위한 의료용 방사선 피 폭은 급격히 증가하고 있고 이에 대한 관리방안으로 방사선 피폭량을 기록하고 있는 실정이다. 국제 기구 인 IAEA는 radiation protection of patients라는 명제 하 에 환자의 방사선 피폭 관리에 대한 홍보 및 교육 에 힘쓰고 있다. IAEA에서는 2002년 International action plan for the radiation protection of patients을 출간하고 2 년 마다 위원회를 구성하여 그 사업 방향을 재조정하 고 있다 ${ }^{[27]}$. 핵심내용은 IAEA는 환자의 방사선 피폭 관리에 관한 자료를 웹사이트(http://rpop.iaea. org)에 공개하고 영상 검사에 사용되는 방사선 양의 과다를 표준화하기 위하여 참조준위(diagnostic reference level) 의 개념을 도입하고 있다. CT장비는 발전하였고 검사 건수, 방사선 피폭량은 급격히 증가하고 있어 현재 진 단에 사용하고 있는 MDCT의 방사선피폭을 감소시키 는 연구가 필요한 실정이다.

이에 따라 본 연구에서는 경상북도 P지역 종합병원 $\mathrm{MDCT}$ 의 방사선피폭선량을 토대로 각 병원에서 사용 하는 CT검사의 환자피폭선량을 분석하여 방사선사의 방사선 위해에 대한 인지도를 높이고, CT검사에 사용 되는 방사선 양의 과다를 표준화에 필요한 선량정보 를 권고선량과 비교하여, $\mathrm{MDCT}$ 의 피폭선량 선량감소
방안으로 제언하고자 한다.

\section{II. 연구방법}

\section{1. 연구대상}

2011년 10월 8일부터 30일까지 포항지역 3개 종합병 원 영상의학과 CT검사 중 무작위로 두부, 복부, 흉부 각 10 건씩 30 건을 대상으로 CTDI, DLP, Slice 수, $\mathrm{DLP} /$ slice 수를 조사하여 병원 별 피폭선량의 차이를 분석을 하였다.

Scan 방법에 따른 기관의 피폭선량측정은 검사 전 연구목적에 동의한 3 명을 대상으로 눈과 갑상선 부위 에 각각 2개씩 4 개의 $\mathrm{TLD}$ 를 부착하고 최초 두부검사 CT Scan은 Helical scan으로 실시하였고, 추적 CT scan 은 고식적 axial scan으로 2회 실시하여 СТ장비에 측정 된 DLP, 눈과 갑상선에 부착한 TLD에 피폭선량을 분 석대상으로 하였다. Scan 방법에 따른 화질의 차이를 분석하고자 Helical scan과 Normal scan으로 얻어 영상 을 10 명의 관찰자가 평가한 부호의 차이를 평가하였 다. 평가자의 구성은 $\mathrm{CT}$ 영상을 많이 경험한 의사 5 명, 방사선사 5 명으로 구성하였고 두 영상의 차이 유, 무를 평가하였다.

\section{2. 분석기기}

연구에 사용된 CT 기종은 $\mathrm{GE}$ 사 의light speed 16(USA), SIMENS사의 SOMATOM Definition AS+128(Germany), TOSHIBA사의 Aquilion(Japan)이다. Scan 방법에 따른 기관의 피폭선량측정은 TOSHIBA사 Aquilion(Japan) CT를 사용하였고 Scan sequence는 C병 원이 통상적으로 사용하는 sequence를 사용하여 Nomal scan은 관전압 $120 \mathrm{kV}$, 관전류 $240 \mathrm{~mA}, \mathrm{Scan}$ 시간 $0.6 \mathrm{sec}$, 검출기 조합은 $0.5 \mathrm{~mm} \times 64$, 영상의 두께는 $4 \mathrm{~mm}$ 로 하여 총 scan시간은 3 초가 소요되었다. Helical scan의 Scan sequence는 관전압 $120 \mathrm{kV}$, 관전류 $240 \mathrm{~mA}, S \mathrm{Scan}$ 시간 $0.6 \mathrm{sec}$, 검출기 조합은 $0.5 \mathrm{~mm} \times 64$, 영상의 두께는 $5 \mathrm{~mm}$ 로 하여 총 scan시간은 5.5 초가 소요 되었다. 기관의 피 폭선량을 측정하기 위해 부착한 TLD는 공인측정기관 인 한일원자력에 의뢰하여 분석하였다. 


\section{3. 자료의 분석}

자료의 분석은 SPSS 12.0 for windows(SPSS Inc., USA)를 이용하여 병원별, 검사부위별 CTDI, DLP, Slice, DLP/slice의 차이를 분석하였고 동일 환자에서 Scan방법에 따른 CTDI, DLP의 차이, 안구 및 갑상선 의 등가선량의 차이를 분석하였다. 분석에는 Student's t-test로 분석하였고, Scan 방법에 따른 화질의 차이는 10 명의 평가자의 평가를 Wilcoxon 부호검정으로 분석 하였다. 통계적 유의수준은 0.05 이하로 하였다.

\section{III. 연구결과}

\section{Abmomen CT의 피폭선량비교}

조사대상 병원의 Abdomen CT 피폭선량을 분석하 여 Table 1과 같은 결과를 얻었다. 조사대상 병원은 CTDI에서 B병원에 비해 A, C병원은 $130 \%, 1471 \%$ 순 으로 유의하게 높았다( $\mathrm{p}<0.05, \mathrm{p}<0.01)$. DLP에서는 B 병 원에 비해 A, C병원은 $143 \%, 225.7 \%$ 순으로 유의하게 높았다(p<0.01). Slice 수는 B병원에 비해 A 병원은 13\% 적었고, $\mathrm{C}$ 병원도 $20.9 \%$ 유의하게 낮았다( $\mathrm{p}<0.01)$. DLP 를 Slice 수로 나눈 값은 B병원에 비해 $\mathrm{A}, \mathrm{C}$ 병원은 $160 \%, 276.2 \%$ 순으로 유의하게 높았다( $\mathrm{p}<0.01)$. 이러한 결과는 조사대상병원에서 사용하는 Abdomen CT의 프 로토콜의 차이가 유의한 차이가 있음을 의미하며, C병 원은 A, B병원에 비해 CTDI, DLP는 높았지만 Slice 수 는 오히려 적어 높은 관전류 또는 낮은 pitch를 사용하 여 피폭선량이 증가함을 알려주는 결과이다.

Table 1. Compared of CTDI, DLP, Slice number, DLP/Slice number from Brain Computed Tomography of surveyed Hospitals.

\begin{tabular}{ccccc}
\hline & CTDI(mGy) & DLP(mGy.cm) & Slice number & DLP/slice \\
\hline a & $10.5 \pm 2.6$ & $1609.8 \pm 673.2$ & $233.4 \pm 47.2$ & $6.7 \pm 1.4$ \\
b & $8.1 \pm 0.7^{*}$ & $1129.4 \pm 104.9$ & $268.9 \pm 11.7$ & $4.2 \pm 0.4^{* * * *}$ \\
c & $119.2 \pm 85.5^{* * * \#}$ & $2549.6 \pm 1217.5^{\#}$ & $212.8 \pm 45.0^{\#}$ & $11.6 \pm 3.4^{* * \# \#}$ \\
\hline
\end{tabular}

Significantly different from the a group by t-test $\left.{ }^{* * *} ; p<0.01\right)$ Significantly different from the $b$ group by t-test $\left({ }^{\# \#} ; p<0.01\right)$

\section{Chest CT의 피폭선량비교}

조사대상 병원의 Chest CT 피폭선량을 분석하여 Table 2과 같은 결과를 얻었다. 조사대상 병원은 CTDI 에서 B병원에 비해 A, C병원은 $127.5 \%, 830.4 \%$ 순으로 유의하게 높았다( $\mathrm{p}<0.01)$. DLP에서는 B 병원에 비해 A 병원 $99.6 \%$ 로 비슷하였으나 C병원은 $253.4 \%$ 로 유의하 게 높았다( $<<0.01)$. Slice 수는 B병원에 비해 A병원은 $58.8 \%$ 적었고, C병원도 $18.8 \%$ 적었다. Slice 수는 B, C 병원 모두 $\mathrm{A}$ 병원에 비해 유의하게 낮았다 $(\mathrm{p}<0.01)$. DLP를 Slice 수로 나눈 값은 B 병원에 비해 A, C병원은 $236.4 \%, 313.6 \%$ 순으로 유의하게 높았다 $(\mathrm{p}<0.01)$. 이러 한 결과는 Abdomen CT와 비슷한 결과이다. A병원은 $\mathrm{B}, \mathrm{C}$ 병원에 비해 Slice 수는 적게 검사하지만 높은 관 전류 또는 낮은 pitch를 사용하고 있음을 의미하고 B 병원 관전류의 사용은 낮지만 검사의 Slice 수가 많아 $\mathrm{A}$ 병원과 B병원은 비슷한 DLP를 보였다. C병원 A병원 에 비해 검사 Slice 수 및 CTDI가 높아 피폭선량이 증 가함을 알려주는 결과이다.

Table 2. Compared of CTDI, DLP, Slice number, DLP/Slice number from Chest Computed Tomography of surveyedHospitals.

\begin{tabular}{ccccc}
\hline & CTOI & DLP & Slice & DLP/slice \\
\hline a & $8.8 \pm 1.0$ & $540.4 \pm 432.7$ & $100.5 \pm 70.5$ & $5.2 \pm 0.9$ \\
b & $6.9 \pm 0.3^{* *}$ & $542.3 \pm 21.1$ & $243.7 \pm 14.0^{* *}$ & $2.2 \pm 0.2^{* * *}$ \\
c & $57.3 \pm 17.0^{* * * \#}$ & $1374.4 \pm 464.4^{* * \#}$ & $198.0 \pm 16.2^{* * \# \#}$ & $6.9 \pm 2.2^{* \# \#}$ \\
\hline
\end{tabular}

Significantly different from the a group by t-test $\left.{ }^{* *} ; p<0.01\right)$ Significantly different from the $b$ group by t-test ${ }^{\# \#} ; p<0.01$ )

\section{Brain $\mathrm{CT}$ 의 피폭선량비교}

조사대상 병원의 Brain CT 피폭선량을 분석하여 Table 3 과 같은 결과를 얻었다. 조사대상 병원은 CTDI 에서 A병원에 비해 B, C병원은 $198.2 \%, 211.3 \%$ 순으로 유의하게 높았다( $\mathrm{p}<0.01)$. DLP에서는 $\mathrm{A}$ 병원에 비해 B, C병원은 $218.4 \%, 243.3 \%$ 순으로 유의하게 높았다 ( $\mathrm{p}<0.01)$. Slice 수는 A병원에 비해 B, C병원은 $108.7 \%$, $216.6 \%$ 순으로 높았다. DLP를 Slice 수로 나눈 값은 A 병원에 비해 B 병원은 $200.6 \%$ 유의하게 높았다( $\mathrm{p}<0.01)$. 
C병원도 $114.1 \%$ 높았으나 유의성은 없었고, B병원에 비하여 유의하게 높아 $\mathrm{C}$ 병원은 $\mathrm{A}, \mathrm{C}$ 병원과 유의한 차 이를 보였다. 이러한 결과는 $\mathrm{C}$ 병원은 $\mathrm{A}, \mathrm{B}$ 병원에 비해 Slice 수는 적게 검사하지만 높은 관전류를 사용하고 있 음을 의미하고 관전류 또는 낮은 pitch의 사용으로 CTDI가 높아 피폭선량이 증가함을 알려주는 결과이다.

Table 3. Compared of CTDI, DLP, Slice number, DLP/Slice number from Abdomen Computed Tomography of surveyed Hospitals.

\begin{tabular}{|c|c|c|c|c|}
\hline & CTOIvol (mGy) & DLP & Slice & DLP/slice \\
\hline a & $32.6 \pm 0.6$ & $470.1 \pm 01$ & $28.9 \pm 0.3$ & $16.3 \pm 0.2$ \\
\hline$b$ & $64.6 \pm 0.5^{* * *}$ & $1026.9 \pm 58.4^{* * *}$ & $31.4 \pm 1.6^{* * *}$ & $32.7 \pm 1.4^{* * *}$ \\
\hline c & $68.9 \pm 18.7^{* * * *}$ & $1143.8 \pm 291.1^{* * *}$ & $62.6 \pm 11.1^{\# \# * * * *}$ & $18.6 \pm 5.2^{\# \# \# ~}$ \\
\hline
\end{tabular}

Significantly different from the a group by t-test $\left({ }^{* * *} ; p<0.01\right)$ Significantly different from the $b$ group by t-test $\left({ }^{\# \#} ; p<0.01\right)$

\section{Scan방법에 따른 두부CT 선량의 비교}

Scan 방법에 따른 두부CT의 피폭선량 차이를 분석 하여 Table 4과 같은 결과를 얻었다. Scan sequence는 통상적으로 사용하는 Normal scan과 Helical scan의 sequence를 사용하였고 총 Scan 시간은 Normal scan이 3 초로 Helical scan 5.5초에 비해 짧았으나 inter scan time으로 인해 전체검사 시간에는 차이가 없었다. Scan 을 시행하고 피폭선량을 분석한 결과 고식적 Normal scan에 비해 Helical scan에서 CTDI, DLP가 각각 $63.4 \%$, $93.7 \%$ 높은 선량을 보였다 $(\mathrm{p}<0.05, \mathrm{p}<0.01)$. 눈의 피폭 선량은 고식적 Normal scan에 비해 Helical scan에서 피 부표면에서 $15.8 \%$ 심부에서 $3.1 \%$ 로 경미한 선량의 증 가가 측정되었다. 그러나 갑상선의 피폭선량은 Helical scan에 비해 고식적 Normal scan이 피부표면 및 심부에 서 각각 $87.26 \%, 88.3 \%$ 선량의 증가가 측정되었다 $(\mathrm{p}<0.01)$. 이러한 결과는 Helical scan에서 총 scan시간이 길고 사용하는 cone beam의 영향으로 중심부에 비해 말단부의 선량이 감소한 결과로 분석된다.
Table 4. Compared of CTDI, DLP, eyeball and thyroid dose from Helical scan with Normal scan.

\begin{tabular}{lcccccc}
\hline & & \multicolumn{2}{c}{ Eye bal I(mSV) } & \multicolumn{2}{c}{ Thyroid(mSv) } \\
& CTDI (mGy) & DLP(cm mGy) & skin & deep & skin & deep \\
\hline $\begin{array}{c}\text { Normal } \\
\text { scan }\end{array}$ & $50.4 \pm 1.3$ & $799.5 \pm 26.8$ & $70.6 \pm 3.8$ & $82.5 \pm 3.7$ & $4.77 \pm 0.4$ & $4.65 \pm 0.7$ \\
$\begin{array}{l}\text { Hel ical } \\
\text { scan }\end{array}$ & $82.4 \pm 4.1^{*}$ & $1549 \pm 86.2^{* * *}$ & $81.8 \pm 2.5$ & $85.4 \pm 4.2$ & $2.55 \pm 0.7^{* *}$ & $2.47 \pm 0.6^{* *}$ \\
\hline
\end{tabular}

Significantly different from the Normal scan by t-test $\left(^{*} ; p<0.05\right.$, *; $p<0.01)$ )

\section{Scan방법에 따른 두부CT 영상의 평가}

Scan 방법에 따른 두부CT의 피폭선량 차이를 분석 하여 fig. 1 과 같은 영상을 얻었고. 화질의 평가는 Table 5 와 같다. 화질을 평가한 평가자 10 명 중 Normal scan 영상이 우수하다 6명, Helical scan의 영상이 우수하다 2 명, 두 영상의 차이가 없다가 2명으로 Normal scan 영 상의 화질이 높게 평가 되었으나 wilcoxon 부호검정을 실시한 결과 통계적으로 두 영상의 화질은 유의한 차 이가 없었다.

Table 5. Difference of image quality of Helical scan image with Normal scan image

\begin{tabular}{cccc}
\hline & 화질의 차이 & 빈도 & 유의확률 \\
\hline Helical scan & 음수 차 & 2 & \\
영상에 비해 & 양수 차 & 6 & 0.289 \\
Normal scan & 동 율 & 2 & \\
영상이 & 합 계 & 10 & \\
우수하다 &
\end{tabular}

*; Wi Icoxon signed-rank test

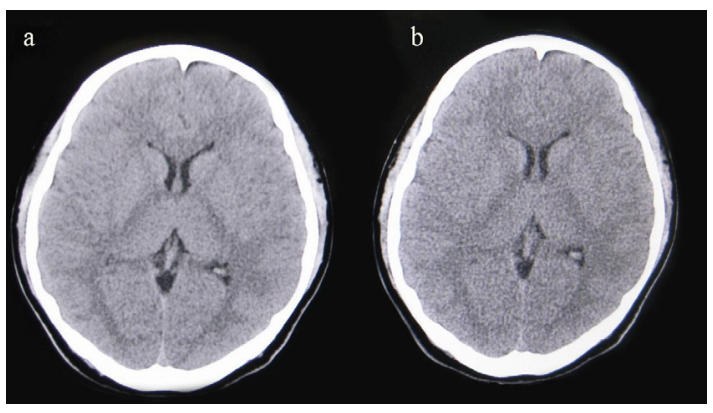

Fig 1. Image of Brain CT. a; Helical scan b; Normal scan 


\section{$\mathrm{IV}$, 고찰}

2009년 보건복지가족부의 자료에 의하면 방사선검 사건수 중 CT 검사건수는 전체 방사선검사건수의 약 $13 \%$ 이고 방사선량 기준으로 의료피폭의 약 $30 \%$ 정도 는 CT검사 때문인 것으로 보고하고 있다. CT장비는 다중검출기로 빠르게 변모하여 최근에는 640 개의 검 출기가 장착된 MDCT도 보급되고 있다. 이러한 $\mathrm{CT}$ 의 발전은 단일검출기 CT로는 검사 할 수 없었던 관상동 맥, 폐혈관색전증에서 가장 정확한 진단율을 가지는 가장 처음 시행해야 하는 검사가 되었다. 또한 CT검사 방법에도 많은 변화를 가져와 Normal scan에 비해 검 사시간의 단축, 재검사률의 감소, 1 일 검사건수의 증 가, 조영효과의 증대 등의 장점이 있는 Helical scan을 선호하게 되었다. MDCT는 여러 가지 장점이 있음에 도 불구하고 장치 하드웨어의 문제로 X-선관과 검출 기의 거리가 가까워지고, 검사의 고속화와, 더욱 얇은 슬라이스 두께를 이용하므로 이에 따른 잡음이나 화 질 향상을 위해 방사선 피폭선량이 높다는 연구결과 가 보고되었다 ${ }^{[19],[23],[25]}$. 소아phantom을 이용한 실험에 서 16MDCT로 두경부, 복부 등 4 부위를 Axial 과 Helical scan으로 검사하였을 때 Overranging에 의해 방 사선 피폭이 26-43\% 증가를 보고하고 있어 ${ }^{[24]}$, Helical scan의 증가는 곧 환자 피폭선량의 증가를 야기한다. 그러나 진단 영상의학검사는 손해보다는 이득이 많다 는 정당성이 확보된 하에 시행되고, 환자의 의료상 방 사선 피폭은 불가피하므로 환자의 피폭은 개인 선량 한도의 적용대상이 아니다 ${ }^{[6]}$. 자칫 피폭선량의 심각성 을 잃을 수 있다.

방사선에 의한 장해는 확률적 영향과 비확률적 영 향으로 분류할 수 있고 진단영역에서는 확률적 장해 를 감소시키기 위하여 방어의 최적화를 요구하여 왔 다. 2009년 미국 Food and Drug Administra-tion은 뇌관 류 CT (brain perfusion CT)를 시행한 수십 명 의 환자 에서 띠 모양의 탈모가 발생한 사실을 밝히며, 정상 적인 경우보다 최대 8 배의 방사선이 노출된 것이 원인 인 것으로 경고한 바 있어 이제는 CT에 의한 방사선 위해 중 결정적 영향 역시 무시할 수 없는 것으로 인 식이 바뀌고 있다 ${ }^{[26]}$.
CT검사는 다양한 임상 적응증에 따라 다양한 검사 프로 토콜이 있고 이에 따라 환자선량도 다양할 수 밖 에 없다. 따라서 임상 적응증에 따라 꼭 필요한 부분만 검사하는 최적화 된 프로토콜을 가지고 있는 것이 중 요하다 ${ }^{[12],[14]}$. 국제 기구 인 IAEA는 환자의 방사선 보 호를 위하여 환자의 방사선 피폭 관리에 대한 홍보 및 교육에 힘쓰고 있다. 환자의 방사선 피폭 관리에 관한 자료를 웹사이트에 공개하고 영상검사에 사용되는 방 사선 양은 다양하며 일부에서 과다하게 사용되고 있어 이것의 표준화를 위하여 참조준위(diagnostic reference level)의 개념을 도입하고 있다. 우리나라에서도 2009년 CT 엑스선검사에서 환자선량 권고량 가이드라인을 발 표하며 의료방사선에서 환자선량을 감소시키려 노력하 고 있다. 이러한 노력에도 불구하고 병원 간 CT피폭선 량은 큰 차이를 보이고 피폭선량관리에 대한 규정이 없어 국민적 불안감이 증폭되고 있다 ${ }^{[28]}$.

이번 연구에서는 일지역의 종합병원을 대상으로 $\mathrm{MDCT}$ 검사 중 두부, 흉부, 복부CT의 피폭선량을 토 대로 병원 간의 선량차이 및 검사방법에 따른 차이를 분석하고, 참조준위와 비교하여 CT검사의 표준화의 필요성을 분석하고자 하였다.

두부CT에서 조사대상 병원의 3 분의 2 에서 CTDI 참 조준위(IAEA $50 \mathrm{mGy}$, 우리나라 $60 \mathrm{mGy}$ )를 초과하지 않 은 A병원에 비하여 유의하게 높았다( $\mathrm{p}<0.001)$. DLP에 서 조사병원의 3 분의 1 은 참조준위 IAEA $1,050 \mathrm{mGy} . \mathrm{cm}$, 우리나라 $1,000 \mathrm{mGy} . \mathrm{cm}$ 의 권고량 보다 높았고, 3 분의 2 가 우리나라의 권고량을 초과하고 있었다. 참조준위를 초과하지 않은 $\mathrm{A}$ 병원에 비하여 유의하게 높았다 $(\mathrm{p}<0.001)$.

Abdomen CT에서도 3분의 1은 CTDI 참조준위 IAEA $25 \mathrm{mGy}$, 우리나라 $20 \mathrm{mGy}$ 보다 높은 $119 \mathrm{mGy}$ 를 보 였고, DLP에서는 모든 조사대상 병원이 우리나라 권 고량 $700 \mathrm{mGy} . \mathrm{cm}$ 보다 높았다. 조사대상 병원 중 모든 검사에서 높은 선량을 보인 $\mathrm{C}$ 병원은 $\mathrm{MPR}, 3 \mathrm{D}$ 검사의 비중이 높아 낮은 pitch, 높은 관전류 검사로 인한 피 폭선량이 높았다. 이 병원은 흥부CT에서도 CTDI $57 \mathrm{mGy}$, DLP $1,374 \mathrm{mGy} . \mathrm{cm}$ 로 높아 전체적으로 피폭선 량이 많은 프로토콜을 사용하고 있음을 알 수 있다. 그러나 검사에 대한 피폭선량은 환자의 상태, 질병, 환 자의 이익, 환자의 크기 등 전체적인 것을 토대로 평 
가하여 피폭선량의 많고 적음을 평가하는 것이 마땅 하다. 선행연구에서 관상동맥CT에서 선량을 줄이기 위한 가장 간단한 방법은 환자의 체중을 적용하는 파 라메터를 지정의 필요성을 제기하였다 ${ }^{[18]}$. 국제원자력 기구인 IAEA는 환자의 방사선피폭 관리를 위하여 자 료의 공개를 하고 참조준위의 개념을 도입하고 있고 많은 선진국에서 피폭선량의 공개를 규정하고 있어 우리나라에서도 검사에 따른 피폭선량을 공개하여 CT 검사를 표준화하는 유도하는 것이 필요하였다. 종합병 원의 대부분은 병원평가인증제 및 병원서비스 평가를 통해 서비스의 질을 평가받고 있다. 이런 공개적인 평 가에 피폭선량의 관리 및 공개여부를 추가하는 제도 적 뒷받침이 필요하다.

두부CT에서 Normal scan과 Helical scan을 비교하여 분석한 결과 CTDI, DLP가 각각 $63.4 \%, 93.7 \%$ 높은 선 량을 보였다 $(\mathrm{p}<0.05, \mathrm{p}<0.01)$. 그러나 갑상선의 피폭선 량은 Normal scan이 $87.26 \%$ 높았다. Helical CT의 선속 은 종심부와 변연부의 모양이 종의 형태를 취하고 있 어 중심선속에서 벗어난 갑상선은 적은 선량으로 피 폭되고, Helical scan시 Gantry 각을 수직으로 사용하여 Normal scan시 OML(Orbitomeatal line)에 평행하게 정렬 된 Gantry 각에 비해 갑상선 피폭선량이 감소하게 하 였다. 그러나 본 연구에서 사용된 프로토콜은 식약청 의 표준준위에 비해 높은 피폭선량을 보였다.

Scan 방법에 따른 두부CT의 영상의 차이는 10 명의 평가자 중 $60 \%$ 가 Normal scan 영상이 우수하게 평가 하였으나 wilcoxon 부호검정을 실시한 결과 통계적으 로 두 영상의 화질은 유의한 차이를 없었다. 2007년 건 강보험 심사평원의 연보에 의하면 두두CT는 633,218건 으로 전체 CT의 $55.2 \%$ 를 차지하고 있다. 두부CT 검사 는 환자의 크기 및 검사프로토콜의 차이가 다른 CT검 사에 비해 차이가 적고 Scan 방법에 따른 화질의 차이 도 없는 것으로 분석되어 Helical scan과 Normal scan의 표준화된 프로토콜의 연구가 필요하고 Normal scan의 사용은 피폭선량을 감소시킬 수 있다. 그러나 갑상선 의 피폭선량은 두부CT에서 발생한 산란선으로 인하여 Normal scan에서 증가함을 TLD로 확인 할 수 있었다. 이와 관련하여 CT검사에서 보호장구를 사용한 경우 환자선량을 $38 \%$ 까지 낮출 수 있다는 보고도 있다 ${ }^{[11]}$. 갑상선은 방사선에 취약한 조직으로 방사선 피폭은
갑상선 암의 증가 원인으로 ${ }^{[15]}$. CT검사에서 방사선에 의한 갑상선 보호를 위한 갑상선보호구의 착용이 필 요하였다.

방사선량 기준으로 의료피폭의 약 $30 \%$ 정도는 CT검 사 때문인 것으로 보고하고 있고 있으나 국제기구의 권 고, 많은 선진국에서 피폭선량의 감소를 위한 노력에 비하여 우리나라의 피폭선량 저감노력은 부족한 것으 로 판단된다. 대부분의 $\mathrm{MDCT}$ 에서 $\mathrm{CT}$ 촬영 Parameter를 기반으로 수학적 계산을 이용하는 팬텀으로 예측선량 을 계산하여 CTDIvol과 DLP를 CT콘솔에서 보여주고 있어 각 환자의 검사에서 환자선량을 추정할 수 있어 ${ }^{[2]}$ 다른 기기를 사용하지 않아도 피폭선량은 알 수 있다. 투시조영검사에서 DAP에 변환계수(conversion factor)를 곱하여 얻은 값이 열형광 선량계(thermoluminescent dosimeter, TLD)로 직접 측정한 방사선량과 비교하여 많 은 차이가 없다고 보고 하였다 ${ }^{[10]}$. 이번 연구에 사용된 DLP는 CT장비에서 보여주는 값을 사용하였고 방사선 사가 CT피폭선량을 관리하는데 별다른 측정기가 필요 하지 않았다. 방사선의 사용에 대한 많은 규제도 필요 하겠지만 무엇보다 우선시 되어야 할 것은 의료용 방사 선피폭으로 이익을 보게 되는 환자의 알권리를 충족시 키는 자료의 공개가 필요하고 행위의 최적화를 위한 방 사선사의 노력이 필요하였다. 방사선사는 CT검사에서 영상의 화질에 대하여 우선시 할 수 있고 이러한 결과 는 잡음의 감소를 판단하게 되고 보다 높은 방사선량을 사용하는 프로토콜을 사용하게 된다. 영상의 최종적인 결과를 판독하는 의사들 역시 환자의 피폭선량보다 화 질을 우선시 한다는 보고가 있어 피폭선량의 공개는 필 요하였다.

본 연구에서는 일지역의 CT검사 중 일부를 조사하 여 분석하였으므로 CT검사의 전체를 평가하는데 무리 가 있었다. 다만 경우에 따라 환자피폭선량의 가이드 권고량을 초과하고 있음을 알 수 있었고, 병원 간의 피폭선량 편차도 있음을 확인 할 수 있었다.

CT검사가 꼭 필요해서 검사를 시행하는 경우가 증 가하고 있어 피폭선량의 증가는 피할 수 없으나 검사 의 목적에 맞으면서 최소한의 선량으로 검사를 시행 할 수 있는 프로토콜을 사용이 필요하다. 이를 위해서 의사는 CT검사로 인한 환자의 이득에 대한 의학적 판 단과 방사선 피폭의 위험성에 대하여 잘 알고 환자의 
이득이 있다는 것을 판단하는 행위의 정당성을 확보 하여야 한다. 영상의학과 의사 및 방사선사는 영상화 질과 관련되어 있는 요소를 알고 $\mathrm{CT}$ 방사선량을 줄이 는 최적화된 프로토콜로 CT검사를 시행해야 하고 환 자의 알권리를 위하여 피폭선량은 공개되어야 한다. 그러나 아직 많은 의사들과 방사선사는 이에 대한 인 식이 부족하므로 이를 위한 교육프로그램이 필요하고 우리나라에서도 검사에 따른 피폭선량을 공개하여 CT 검사를 표준화하는 유도하는 것이 필요하였다.

\section{$\mathrm{V}$. 요약 및 결론}

이번 연구에서는 2011년 10 월 8 일부터 30 일까지 포 항지역 3 개 종합병원 영상의학과 CT검사 중 무작위로 두부, 복부, 흉부 각 10 건씩 30 건을 대상으로 CTDI, DLP, Slice 수, DLP/slice 수를 조사하여 병원 별 피폭 선량의 차이를 분석하여 다음과 같은 결론을 얻었다.

첫째, Brain CT에서 조사대상 병원의 3분의 2에서 CTDI 참조준위(IAEA $50 \mathrm{mGy}$, 우리나라 $60 \mathrm{mGy}$ )를 초 과하지 않은 병원에 비하여 유의하게 높았다 $(\mathrm{p}<0.001)$. DLP에서 조사병원의 3 분의 1 은 참조준위(IAEA $1,050 \mathrm{mGy} . \mathrm{cm}$, 우리나라 $1,000 \mathrm{mGy} . \mathrm{cm})$ 의 권고량 보다 높았고, 3 분의 2 가 우리나라의 권고량을 초과하고 있 었다.

둘쩨, Abdomen CT에서도 3분의 1은 CTDI 참조준 위 IAEA $25 \mathrm{mGy}$, 우리나라 $20 \mathrm{mGy}$ 보다 높은 $119 \mathrm{mGy}$ 를 보였고, DLP에서는 모든 조사대상 병원이 참조준위 우리나라 권고량 $700 \mathrm{mG}$.cm보다 높았다.

셋째, 조사대상 병원 중 모든 검사에서 높은 선량을 보인 $\mathrm{C}$ 병원은 $\mathrm{MPR}, 3 \mathrm{D}$ 검사의 비중이 높아 낮은 pitch, 높은 관전류 검사로 인한 피폭선량이 높았다. 이 병원은 전체적으로 피폭선량이 많은 프로토콜을 사용 하고 있음을 알 수 있었다.

넷째, 두부CT에서 Normal scan과 Helical scan을 비교 하여 분석한 결과 Helical CT가 CTDI, DLP가 각각 $63.4 \%, 93.7 \%$ 높은 선량을 보였다 $(\mathrm{p}<0.05, \mathrm{p}<0.01)$. 그러 나 갑상선의 피폭선량은 Normal scan이 $87.26 \%$ 높았고, 갑상선 보호구의 착용이 필요하였다.

다섯째, Scan 방법에 따른 두부CT의 영상의 차이는
10 명의 평가자 중 $60 \%$ 가 Normal scan 영상이 우수하 게 평가 하였으나 wilcoxon 부호검정을 실시한 결과 통계적으로 두 영상의 화질은 유의한 차이를 없었다.

이상의 결과를 종합하면 많은 병원에서 $\mathrm{MDCT}$ 의 피폭선량이 우리나라의 참조준위를 초과하고 있을 것 으로 판단되며, 영상의학과 의사 및 방사선사는 영상 화질과 관련되어 있는 요소를 알고 CT 방사선량을 줄 이는 최적화된 프로토콜로 CT검사를 시행해야 하고 환자의 알권리를 위하여 피폭선량은 공개되어야 한다. 그러나 아직 많은 의사들과 방사선사는 이에 대한 인 식이 부족하므로 이를 위한 교육프로그램이 필요하고 우리나라에서도 검사에 따른 피폭선량을 공개하여 CT 검사를 표준화를 유도하는 것이 필요하였다.

\section{참고문헌}

[1] California S. B., radiation dosage, California S.B. 1237, 2010.

[2] Jung SE, Korean Institute for Accreditation of Medical Image. National survey of radiation dose of computed tomography in Korea, Seoul: Korea Food and Drug Administration, 2008.

[3] NCRP report, National Council on Radiation Protection and Measurements, Ionizing radiation exposure of the population of the United States: NCRP report no. 160. Bethesda: National Council on Radiation Protection and Measurements, 2006.

[4] Valentin J, International Commission on Radiological Protection, The 2007 recommendations of the International Commission on Radiological Protection. Amsterdam Elsevier, 2007.

[5] 김영옥, 64 slice $\mathrm{MDCT}$ 장비 제조사별 automatic exposure conrtral적용 시 radiation dose와 image quality에 관한 연구, 고려대학교 대학원 석사학위논문, 2010.

[6] 남진현, 64slice MDCT에서의 선량측정 및 선량관리 프로그램에 관한 고찰, 고려대학교 의용과학대학원 석사학위논문, 2010

[7] 보건복지가족부, 식품의약품안전평가원, 대한영상의학회, 대한방사선사협회, $\mathrm{CT}$ 엑스선 검사에서의 환자선량 권고량 가이드라인, 방사선안전관리시리즈, Vol. 19, pp.1-51, 2009.

[8] 안정희, Multi-DetectorComputed Tomography(MDCT)에 의한 신체부위별 노출 방사선량 측정, 경북대학교 보건대학원 석사학위논문, 2011.

[9] 임청환, 전산화단층촬영의 방사선피폭에 의한 위험도 추정, 원광대학교 의료경영대학원 박사학위논문, 2004.

[10] Bor D, Sancak T, Olgar T, Elcim Y, Adanali A, Sanlidilek U, 
Akyar S, Comparison of effective doses obtained from dose-area product and air kerma measurements in interventional radiology, Br. J. Radiol, Vol. 77, pp.15-322, 2004.

[11] Curtis JR, Computed tomography shielding methods: a lite-rature review, Radiol Technol, Vol. 81, pp.428-436, 2010.

[12] Dougeni E, Faulkner K, Panayiotakis G, A review of patient dose and optimisation methods in adult and paediatric CT scanning, Eur. J. Radiol, Vol. 16, 2011.

[13] Lee CI, Haims AH, Monico EP, Brink JA, Forman HP. Dia-gnostic CT scans: assessment of patient, physician, and radiologist awareness of radiation dose and possible risks. Radiology, Vol. 231, pp.393-398, 2004.

[14] Payne JT, CT radiation dose and image quality. Radiol Clin North Am., Vol. 43, No. 7, pp.953-962, 2005.

[15] Pierce DA, Preston DL, Radiation-related cancer risks at low doses among atomic bomb survivors, Radiat Res. Vol. 154, pp.178-186, 2000.

[16] Rubins JB, The current approach to the diagnosis of pulmonary embolism: lessons from PIOPED II, Postgrad Med, Vol. 120, pp.1-7, 2008.

[17] Stein PD, Woodard PK, Weg JG, Wakefield TW, Tapson VF, Sostman HD, Sos TA, Quinn DA, Leeper KV, Hull RD, Hales CA, Gottschalk A, GoodmanLR, Fowler SE, Buckley JD, PIOPED II Investigators. Diagnostic pathways in acute pulmonary embolism: recommendations of the PIOPED II Inves-tigators, Radiology, Vol. 242, No. 27, pp.15-21, 2007.

[18] 강영한, 64-slice single source CT와 128-slice dual source CT를 이용한 관상동맥 조영 검사 시 환자선량 비교, 한국방사선학회, Vol. 6, No. 2, pp129-136, 2012.

[19] 권대철, 이종석, 유병규, 흥부 및 복부에서 $\mathrm{AEC}$ 적용에 따른 $\mathrm{MDCT}$ 의 선량 감소효과, 한국콘텐츠학회논문지, Vol. 9, No. 3, pp224-231, 2009.

[20] 박용구, 정승은, CT검사의 방사선피폭과 저감화 방법, 대한의사학회지, Vol. 54, No. 12, pp1262-1268, 2011.

[21] 보건복지가족부, 식품의약품안전평가원, 대한영상의학회, 대한방사선사협회, $\mathrm{CT}$ 엑스선 검사에서의 환자선량 권고량 가이드라인, 방사선안전관리시리즈, No. 19, pp.1-51, 2009.

[22] 이활, 의료방사선의 현재와 각국의 피폭저감화 활동사항, 대한의사협회지, Vol. 54, No. 12, pp.1248-1252, 2011.

[23] 임청환, 조정근, 이만구, 전산화단층촬영 검사의 방사선 선량에 관한 연구, 방사선기술과학, Vol. 30 , No. 4, pp.81-389, 2007.

[24] 정아영, 소아 CT엑스선검사에서의 환자선량 저감방안,
식품의약품안전평가원, Vol. 18, No. 2, 2011.

[25] 한동균, 고신관, 양한준, 김문찬, $\mathrm{MDCT}$ 에서 화질과 방사선량에 관한 연구, 방사선기술과학, Vol. 30, No. 2, pp.129-138, 2007.

[26] Food and Drug Administration, Safety investigation of CT brain perfusion scans,

http://www.fda.gov/MedicalDevices/Safety/AlertsandNotices/ ucm185898.htm.

[27] Vienna: International Atomic Energy Agency, International action plan for the radiation protection of patients, from:http://rpop.iaea.org/RPOP/RPoP/Content/ArchivedNews/Report Steering Panel.htm.

[28] 헬스조선, CT방사선량 환자에게 알려야, CT 방사선 논란 '여전', http://health.chosun.com/news/dailynews_view.jsp?mn_idx=40075 